Susan Metros

\title{
A heart to heart on leadership How to use your life experiences to become a better leader
}

$\mathrm{F}_{\mathrm{n}}^{\mathrm{r}}$ rances Maloy, ACRL president, asked to write this column after she heard me deliver a presentation at the 2004 Frye Leadership Institute titled, "Can you lead with the heart without taking it to heart?" After giving her invitation some thought, I came to the conclusion that librarians do not need another treatise on leadership. At the local bookstore, entire aisles are devoted to book titles promoting everything from The Leadership Secrets of Attila the Hun ${ }^{1}$ to the Leadership Secrets of Santa Claus. ${ }^{2}$ Amazon. com alone offers more than 16,000 books with "leadership" in the title. In an article published in this journal last year, author Eric Shoaf searched Library Literature Online and came up with close to 600 articles on leadership. ${ }^{3}$ Many of these works subscribe to the popular presses' quick-fix formula of following step-by-step directions that lead to becoming a better, albeit generic, leader

Missing from this vast array of "cookiecutter" leadership wisdom is advice on how to glean and mold your own life experiences into a personalized leadership philosophy. This nontraditional approach to leadership takes into account past experiences, current competencies, and future potential. It is built upon a foundation of basic common sense, acquired knowledge, personal disposition, a certain amount of tenacity, and a sprinkling of intuition. To begin, you must first conduct an inventory of your life experiences, identifying those that might hold leadership potential. It is the deconstruction - the picking apart-of these experiences to reveal your underlying values and beliefs that will translate into a customized set of leadership principles. While it would be impossible for me to author an article based on the leadership principles that you bring to the table, I can describe some examples gleaned from my own life experiences. These fall into five categories: perspective, teamwork, creativity, observation, and process.

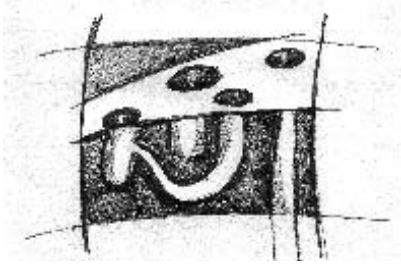

\section{Perspective}

Edward de Bono, a renowned authority in the field of creative thinking, invented the concept of lateral thinking. ${ }^{4} \mathrm{He}$ envisioned it as a nonlinear, generative and provocative process, and differentiated it from vertical thinking, which he described as selective, analytical, and sequential. His followers often refer to the metaphor of digging holes to illustrate the differences between the two methods of thinking. The vertical thinker digs one very deep hole, exploring the topic in its entirety; in contrast, a lateral thinker digs many holes of various circumferences and depths. After surveying the terrain, the lateral thinker might tunnel between holes or combine holes, and then return to the most promising holes for further excavation and exploration.

Susan E. Metros is a professor of design technology and serves as deputy chief information officer and executive director for eLearning at Ohio State University, e-mail: metros.1@osu.edu

○ 2005 Susan E. Metros 
While most academics are vertical thinkers and rewarded for in-depth research within their chosen discipline, I am a self-professed lateral thinker. Initially, I perceived this as a handicap in the academic environment in which I chose to dedicate my life work. However, studying de Bono taught me that being a lateral thinker could work to my advantage. By exploring multiple paths, I readily see the big picture. I can expand my knowledge base, being careful to remember that while I might know a lot about many topics, I am far from expert in but a few.

In my current position as an information technology leader, lateral thinking provides me with the skill to navigate and survey vast landscapes, glutted with data and information, and to make informed decisions. I am proficient with learning and using new technologies because lateral thinking imitates the Web with its infinite network of links. Like my librarian colleagues, I work in a central support unit. As a lateral thinker I can transcend disciplinary boundaries and respond to issues holistically, which, in turn, allows me to better serve the needs of a diverse clientele.

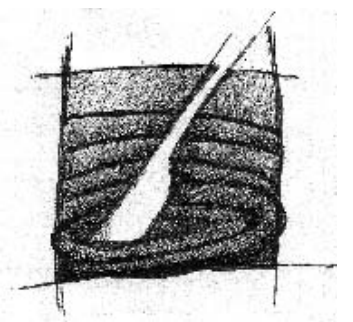

\section{Teamwork}

Five years ago, on one of those first-ofthe-season, pristine spring mornings, I met some friends for Sunday brunch at a popular local restaurant. We were seated outside on the patio, overlooking the river. My attention was drawn to the water below just as a long, sleek boat filled with eight synchronized rowers swiftly glided by. At that moment, I knew I had to learn to row.

While I will never be a great, or, let's be honest, even a very good rower, I can now hold my own as a member of a masters-level crew and can maneuver a single without capsizing most of the time. However, what I have learned, and continue to learn, from rowing has been indispensable to me as a leader.

I have learned about real commitment-your teammates can't take the boat out, let alone carry it, if you don't show up at the boathouse on time. Rowing requires unequivocal trust: you sit facing backwards, and the coxswain serves as your eyes, steering the boat along a clear course and setting the pace. I had never experienced the adrenaline rush of competition until I began rowing. The pure exhilaration of pushing yourself past what you thought was humanly possible to win (or lose) is, in itself, a lesson in leadership.

Rowing has afforded me the privilege of participating in one of the purest forms of collaboration. Eight rowers must stroke with synchronicity and perfect balance to efficiently drive the boat forward. With a lot of teamwork and a little luck, the rowers might experience "swing," a magical phenomenon when the whole transcends the sum of the parts-when you and your team meld into, and row as, one. There is a saying in rowing: "Keep your head in the boat." It means that you must monitor every nuance of your teammates' movements, while fully concentrating on the complexities of your own stroke, all the while making small, continuous, counterbalancing adjustments. Applied to leadership, it is about staying focused and, at the same time, remaining agile and responsive.

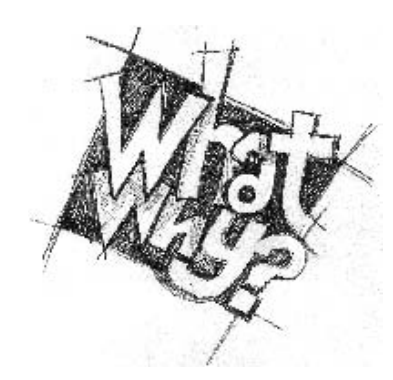

\section{Creativity}

While many of my information technology colleagues graduated with degrees in computer science, business, or engineering, I majored in fine arts followed by a graduate degree in graphic design. I learned early on that the ability to solve problems creatively 
had little to do with business acumen or technological expertise and everything to do with an ability to assimilate creative problem-solving processes into everyday work practice. As I progressed through a series of jobs and took on administrative responsibilities, the ability to think creatively separated inspired management from pedestrian decision-making.

Despite popular belief, the creative problem-solving process is practiced with diligence and rigor. It is a highly structured methodology that swings between analysis and synthesis, and divergent and convergent thinking. There are numerous models based on this duality that offer ways to hone one's creative problem-solving skills. In the seminal book The Universal Traveler, the authors offered more than 60 techniques to support their seven-stage creative problem-solving methodology. 5 For example, they "forced relationships" by asking what would happen if this thing was combined with that thing? They mused about how famous person $\mathrm{X}$ or exotic animal $\mathrm{Y}$ would solve the same problem. They constructed matrices comparing variables to attributes and weighing options against success criteria. They "manipulated verbs" to generate scores of alternativeswhat happens if you shrink it, sell it, turn it upside-down or inside-out? They devised a stretch and squeeze exercise, which posed a chain of questions beginning with "what?" to expand problem solving and "why?" to narrow it down.

In a recent survey of 13,000 upper-level information technology (IT) administrators, key findings indicated that the IT community is a cool climate for innovation. ${ }^{6}$ As a member of that community, I have had to learn to channel creativity to be more tactical, without compromising ingenuity and vision. To encourage my staff to examine problems from a variety of viewpoints prior to making decisions, I try to provide them with enough time to employ creative problem-solving processes - to brainstorm, to "what if?" and to reflect. These kinds of ideation activities are integral to nurturing innovation and ulti- mately result in concrete recommendations, well-conceived strategic plans and sound business cases.

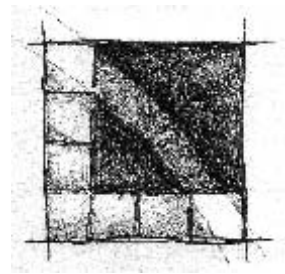

\section{Observation}

Many years ago, I came across the concept of "desire paths," an architectural term describing the dirt-trodden shortcuts people make and take through open spaces. Legend has it that when the Ohio State University campus plan was evolving in the early 1900s, the landscape architects waited to see where students wore paths across the university's central green space (known as the Oval) before permanently paving the user-defined crisscross of pathways.

Academia is fraught with traditions that translate into rigid thinking. The "we have always done it this way" mentalities serve as major obstacles to progress. The analogy of a desire path allows a leader to circumvent the dyed in the wool, prescribed way to accomplishing something. It also provides the opportunity to survey the "landscape" prior to determining what to do. Benjamin Disraeli once proclaimed, "I must follow the people, am I not their leader?" He understood that there was great value in sitting back and observing conditions before acting.

\section{Process}

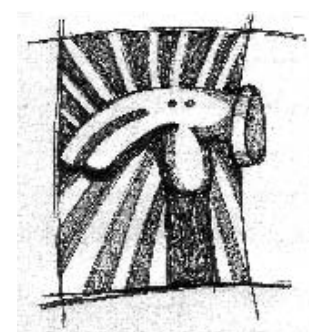

In the late 70s, as a university honors college student, I was entrusted with designing my own curriculum. Interested in the new discipline of environmental design, I enrolled in 
a workshop to build the city of the future called "Arcosanti." Arcosanti, located in the high desert of Arizona, was the brainchild of architect Paulo Soleri. When complete, Arcosanti was to be home to 7,000 citizens who were devoted to demonstrating ways to improve urban conditions and lessen the destructive impact on the earth. Using ecologically sensitive building materials, innovative construction techniques, and experimental energy sources, the city was envisioned to be a self-contained utopia, complete with everything from a shared model for community governance to its own hydroponics garden.

While most of the workshop participants held the same somewhat idealistic ecological and socialistic visions as our guru Soleri, the majority of us had no useful construction skills per se. I labored hard to heft 100pound bags of cement from one location to another, and I learned the intricacies of mixing cement and the physics of laying rebar. Soleri made the approximately 80-mile trek from his air-conditioned architecture offices in Scottsdale to the construction site every Tuesday afternoon. He sat out on the rocks, surrounded by his ragtag disciples, and unfurled beautifully hand-drawn plans, while preaching the fusion between architecture and ecology. During my two-month tenure at Arcosanti I learned that cement goes in and concrete comes out, a clean tool is a happy tool, and most important-process often trumps product.

Today, some 30 years later, Arcosanti is still under construction. However, it now bills itself as an "urban laboratory," exploring an alternative to urban development in the age of environmental crisis. The goal has shifted from completing the city to examining the arcology theory and its ramifications on building the city-process over product.

As it applies to leadership; when undertaking a project, it is important to remember that sometimes the journey can be as valuable, or even more so, than the final destination.

\section{Leading with the heart}

Understandably, your leadership "story" will most likely never make the bestseller list because it is personalized just for you. However, identifying these qualities within yourself will serve you well whether you hold an administrative position or not.

Regardless of your career goals, understanding your own personal motivation will provide you with the ability to think creatively about, and respond appropriately to, the leadership opportunities and challenges that you face daily at work and at home. You can choose to look outward and follow the ready-made advice of others or you can choose to look inward and lead with your heart.

\section{Acknowledgements}

I would like to acknowledge Teri Ryan and Mark Herriot for their grammatical proofing and editorial suggestions.

\section{Notes}

1. Wess Roberts, Leadership Secrets of Attila the Hun (Warner Books, Inc., 1987).

2. Eric Harvey, David Cottrell, Al Lucia and Mike Hourigan, The Leadership Secrets of Santa Claus (The Walk and Talk Company, 2003).

3. Eric Shoaf, "New Leadership for Libraries: Who Has the Right Stuff?" CERL News 65, no. 7 (2004): 363-65, 375.

4. Edward de Bono, Lateral Thinking (Harper Collins, 1969).

5. Dan Koberg and Jim Bagnall, The Universal Traveler: A Soft Systems Guide to Creativity, Problem-Solving, and the Process for Reaching Goals (Los Altos, CA: Crisp Publications, Inc., 1991).

6. Richard Katz and Gail Salaway, "Information Technology Leadership in Higher Education: The Condition of the Community," EDUCAUSE Center for Applied Research (ECAR) Key Findings (January 2004): 1-10.

7. Arcosanti: An Urban Laboratory? www.arcosanti.org. Accessed March 30, 2005. $\pi$ 